\title{
The Stiffness Evaluation of Tracking Solar Power Generator for Wind Load
}

\author{
Youngeun Kim, Kyuwon Jeong \\ Dept. Of Mech. Eng., Chungbuk National University \\ 1 Chungdae-ro, Seowon-gu, Cheongju-si, Chungbuk, Korea \\ youngeun629@naver.com; jeong@chungbuk.ac.kr
}

\section{Extended Abstract}

Since the efficiency of the solar power system is dependent on the incident solar light, the solar modules have to be installed towards the sun.[1] Because the tracking type can adjust the angle of the solar module following the sun, the energy efficiency of this type is good. Since the tracking structure has to be installed outdoors, loads such as self weight, wind load, snow load, earthquake load have to be considered. In this paper, just two kinds of loads; the self weight and wind load, were considered for the simulation. The others were ignored because they are small relatively. The simulation was done using Ansys FEM code.[2-5] Wind load was simulated using the wind speed and the fluid properties set appropriate to the area where the structure was installed. From the simulation they were found how much stresses and deformations were caused by these loads. A series of experiments was conducted to verify the result of the simulation. Strain gages were attached to the position where the large strain value was shown in the simulation.[6,7] Comparing those results the stiffness of the tracker was verified.

\section{References}

[1] G. I. Song, "Solar industry developing status and prospects in RPS," Journal of the KSME, vol. 52, no. 3, pp. 42-46, 2012.

[2] F. R. Menter, "Review of the shear-stress transport turbulence model," International Journal of Computational Fluid Dynamics, vol. 23, no. 4, pp. 305-316, 2009.

[3] J. H. Lee and K. J. Jung, "Aerodynamic analysis of a three-dimensional wing using transition SST turbulence model," Korea Society for Computational Fluids Eng., pp. 45-48, 2010.

[4] ANSYS CFX-SloverModeling Guide, Release 15.0, Ansys Inc., Nov. 2013.

[5] ANSYS Workbench Mechanical Guide. Release 15.0, Ansys Inc., Nov. 2013.

[6] A. C. Ugural, Mechanical Design: an Integrated Approach. Higher Education Press, 2012.

[7] A. V. Ugural, Mechanics of Materials. John Wiley \& Sons Press, 2008. 